\title{
Está FORA DE CAUSA ACABAR BEM* \\ biografemas de uma nem-sempre-possível
}

\author{
Lucia Castello Branco \\ UFMG
}

\begin{abstract}
RESUMO
Descrição de uma prática da letra, realizada na modalidade de oficina, e tendo como método a textualidade de Maria Gabriela Llansol articulada à psicanálise lacaniana.
\end{abstract}

\section{PALAVRAS - CHAVE}

prática da letra, oficina de letras, textualidade, psicanálise lacaniana

\begin{abstract}
"Não atribuam mais, à arte de cerzir sereno da poesia, o epíteto de estranheza, atribuamlhe, vós, oriundos de um país que descobriu mundos, o epíteto de a-nem-sempre-possível que, de extensões conhecidas e desconhecidas dos humanos, nasce o vórtice da Literatura. Há lugares a que nunca chegaremos."
\end{abstract}

(Maria Gabriela Llansol)

$\mathbf{E}_{\text {voco aqui as palavras de Maria Gabriela Llansol para referir-se à Literatura, à }}$ poesia e à tradução, na tentativa de acercar-me de um trabalho delicado a que chamarei, em consonância com Llansol, de "cerzir sereno da poesia". Tomando-o como uma prática "nem-sempre-possível", aproximo essa arte do pensamento de Blanchot, no magnífico ensaio "Está fora de causa acabar bem".

Nesse ensaio, fazendo ecoar as palavras de Goethe, Blanchot nos adverte que, no campo da Literatura, "está fora de causa acabar bem". Afinal, para a Literatura, que obedece sempre à "exigência da obra", ${ }^{1}$ já de início está fora de causa acabar: a obra, nem acabada nem inacabada, é. Que dizer, então, de um "acabar bem”?

Talvez não seja, pois, um final feliz ou um certo bem-estar o que esteja em jogo no campo do literário. Visando antes a um "bem dizer", ou a um "dizer bem", a Literatura, no entanto, resta "maldita": é um campo em que malogramos sempre. Seja porque "malogramos sempre ao falar do que amamos", ${ }^{2}$ seja porque o fracasso - na medida mesmo de um "saber

\footnotetext{
*Texto apresentado no Colóquio LIPSI: Literatura e Psicanálise: o E da questão, dia 6/9/2003.

${ }^{1}$ Sobre o conceito blanchotiano de "exigência da obra", ver Blanchot. O espaço literário, 1987.

${ }^{2}$ BARTHEs. O rumor da língua, p. 300-309: Malogramos sempre ao falar do que amamos.
} 
em fracasso", como o definiu Lacan ${ }^{3}$ - reside na base do trabalho literário, para a Literatura, sempre mal dita, está fora de causa acabar bem.

Mas isso, sabemos, não significa que, no mar de palavras literário, estejamos irremediavelmente destinados a naufragar. Como observa o jovem Goethe, nem sempre se está destinado a afundar-se. ${ }^{4}$

É, pois, tendo como horizonte a obra - esse ponto impossível que nunca atingimos -, sabendo que " há lugares a que nunca chegaremos", que um trabalho de letras - a prática da letra em seu sentido mais literal: o "cerzir sereno da poesia" - pode se desenvolver com pacientes psicóticos.

Nesse horizonte, o que para a Literatura se coloca como um postulado - "está fora de causa acabar bem" - para a Psicanálise deve se manter suspenso como uma questão. Não busquemos respondê-la assim tão rapidamente. Pois se aqui também, no campo da Psicanálise - e, mais especificamente, no campo de uma clínica da psicose - "há lugares a que nunca chegaremos", talvez sejamos obrigados a pensar essa clínica não mais na vertente da "estranheza", mas, quem sabe, através do epíteto de "a-nem-sempre-possível".

\title{
Escrever Não Ler -
}

É conhecida a formulação de Lacan, em "A função do escrito", do escrito como algo para não ser compreendido. Definido como um "pas-à-lire", o escrito habita, para Lacan, o lugar não exatamente de uma ilegibilidade, mas, mais exatamente, de um "não-a-ler". Ocorre que o "não" - o "pas" - é também o "passo", o "passo a ler". Pode-se pensar, da mesma maneira, que é também como um "não a escrever" que se dá o passo de escrita. Disso parecem saber alguns escritores que, como Marguerite Duras, escrevem:

Escrever.

\author{
Não posso. \\ Ninguém pode. \\ É preciso dizer: não se pode. \\ E se escreve. ${ }^{5}$
}

Disso parecia saber a Senhora H., aquela que, desde o primeiro encontro, interpelame com o seu não: "Eu era cheia de vida. Agora não vivo mais. Já escrevi muito. Agora já não escrevo."

"Escrever, não. Ler." Estas são as primeiras ordens que recebo da Senhora H., sem que ela assim as explicite. E, como secretária eficiente, passo a ler com ela os textos que ela escolhe e que um dia, provavelmente, veio a ler: os seus próprios.

\footnotetext{
${ }^{3}$ A respeito do saber em fracasso, Lacan afirma, em "Lituraterra": "Insisto em corrigir meu tiro de dizer: saber em fracasso. É aí onde a Psicanálise mostra o que tem de melhor. Saber em fracasso, como se diz figura em abismo. Isto não quer dizer fracasso do saber (...)”. LACAN. Lituraterra, p. 21.

${ }^{4}$ Blanchot. O livro por vir, p. 36: Está fora de causa acabar bem.

${ }^{5}$ Duras. Escrever, p. 47.
} 
Mas já aí um outro não se interpõe. "Noli me legere", diz-nos Blanchot, a evocar o "Noli me tangere" do Cristo ressuscitado, diante das mãos de Madalena, que se estendem em sua direção, querendo tocar-lhe o corpo.

Não é possível tocar o corpo do pai, não exatamente porque esse corpo seja interdito, mas porque é impossível tocar o que está, perpetuamente, a morrer. E é essa morte o que o Cristo ressuscitado encarna: sua ressurreição encarna menos a presença do morto que torna a viver que a apresentação do vivo que encena, reiteradamente, o estar a morrer. ${ }^{6}$

Da mesma forma, para o escritor é impossível ler-se: "Noli me legere". A obra está sempre aquém ou além daquele que escreve. Impossível tocá-la. Assim, o escritor vai à obra, em busca de tocá-la, mas dela retorna com apenas um livro nas mãos, um amontoado de palavras estéreis e inúteis, como observa Blanchot. ${ }^{7}$ E a Literatura perdura, em seu perviver, como um eterno estar a morrer no texto.

"Ler. Nascer. Morrer. Aprender a viver com a leitura que morre. Ler a língua na estátua de um outro, esperar que o mesmo momento se repita. Não o deixar morrer. Estabelecer um elo entre a lei e a leitura, e querer a escrita."

Evocadas estas palavras de Llansol, imediatamente umas outras, da mesma Senhora $\mathrm{H}$., se fazem escutar. Na verdade, tratam-se das mesmas palavras de antes, mas pontuadas, agora, de outra maneira: "Escrever. Não ler." E assim, por este movimento, começamos, sem mesmo saber que já começáramos antes mesmo de começar. Quando, exatamente?

\section{A palavra começANte -}

"Nunca olhes os bordos de um texto. Tens que começar numa palavra. Numa palavra qualquer se conta (...) Não ligues excessivamente ao sentido. A maior parte das vezes, é impostura da língua". ${ }^{9}$

É preciso uma palavra qualquer que comece. Qualquer uma. E, no entanto, arrancada do nada que o branco do papel desenha, essa "palavra começante" já estava lá. Onde, exatamente? ${ }^{10}$

Lá, quando a encontrei, em meu ofício de escriba - aquela que escreve o que não lê - e de leitora - aquela que lê o que não escreve - para nossa arte do "cerzir sereno da poesia".

Nem sempre tão cerzida e nem sempre tão serena a poesia que, em sua palavra começante, ali me aguardava. Um maço de poemas, cerzidos sem muita serenidade, foi-me apresentado. Eram escritos do estupor da noite, quando, há vinte anos, a insônia, a "noite branca", a atacava. "Noite, noite branca - assim o desastre, essa noite à qual a obscuridade falta sem que a luz a clareie."11

\footnotetext{
${ }^{6} \mathrm{NANCY}$. Noli me tangere.

${ }^{7}$ Blanchot. O espaço literário, p. 13.

${ }^{8}$ Llansol. Um beijo dado mais tarde, p. 51.

${ }^{9}$ LLANSOL. Um beijo dado mais tarde, p. 112-113.

${ }^{10}$ A respeito da "palavra começante", ver Blanchot. La bête de Lascaux.

${ }^{11}$ Blanchot. L'écriture du désastre, p. 8.
} 
A palavra começante, quase uma holófrase, foi-me trazida por um livro de Llansol em que a loucura e o poema se escrevem em sua radicalidade. Trata-se do Hölder, de Hölderlin, livro que a Senhora H. já lera antes de me encontrar e do qual destacara uma frase para me receber. "O amor não tem anel", disse-me ela, tão logo começamos a conversar.

A partir desse texto em que a loucura é definida como "a mente estar com o poema e o corpo ausente", pusemo-nos a trabalhar em torno de uma primeira "coisa-poema". Esta a palavra começante que nos conduzia: "superfície de poema". Este o contexto do qual essa palavra se destaca:

Tinha nas mãos uma porção de excremento humano, que tentava moldar numa superfície de poema; mas a angústia, de modo imerecido, fazia-o saber que a loucura era a mente estar com o poema e o corpo ausente. ${ }^{12}$

Em "O suporte de papel”, precioso relato sobre a experiência da Oficina de Letras com pacientes psicóticos, Cinara de Araújo assinala a importância de um suporte - o suporte de papel - para suportar a potência da escrita. ${ }^{13}$ "Que potência é essa?" - indaga Blanchot. "Não é nem o leitor, nem a sociedade, nem o Estado, nem a cultura. Dar-lhe um nome e realizá-la, na sua própria irrealidade, foi também o problema de Mallarmé. Chamou-lhe o Livro." 14

É, pois, acreditando nessa potência e na eficácia de um suporte de papel que este trabalho - a Oficina de Letras com pacientes psicóticos - se sustenta, enquanto prática da letra, há quinze anos, em Belo Horizonte. ${ }^{15}$

A partir de uma palavra começante, extraída de um livro que me fora trazido agora por ela, a Senhora H., pudemos então começar um trabalho sobre alguma "superfície de poema". Se o poema foi a superfície, o papel foi o suporte. E a obra, o ponto central: "Centro fixo também, que se desloca, é verdade, sem deixar de ser o mesmo e tornando-se sempre mais central, mais esquivo, mais incerto e mais imperioso". ${ }^{16}$ Ponto de ignorância, mas também ponto de desejo daquele que escreve. No entanto, como vislumbrar, naquela que se diz morta, um ponto de desejo? Como arrancar, daquela que tem certeza, um ponto de ignorância?

\section{Je suis vivant. Non, tu es mort.}

$\mathrm{Na}$ surpreendente narrativa L'instant de ma mort, em dado momento, escrevem-se estas palavras: "Je suis vivant. Non, tu es mort." A estas alturas da narrativa, em que se relata a história de um sujeito que teria escapado, milagrosamente, do fuzilamento realizado pelas tropas nazistas, o leitor, se já é capaz de esboçar aí um desenho para a voz narrativa que, oscilando entre a primeira e a terceira pessoas, é gradativamente tomada pelo "neutro"

\footnotetext{
${ }^{12}$ Llansol. Hölder, de Hölderlin.

${ }^{13}$ Araújo. O suporte de papel.

${ }^{14}$ Blanchot. O espaço literário, p. 35.

${ }^{15}$ A esse respeito, ver Branco. (Org.). Coisa de louco.

${ }^{16}$ Blanchot. O espaço literário. Nota de abertura.
} 
- torna a se confundir. Afinal, se há aí um sujeito que diz "Estou vivo", a quem atribuir a voz do outro, que diz: "Não, tu estás morto"?

A quem, senão ao próprio sujeito que, interpelado pela cena e pelo instante de sua morte, descobre-se morto justamente no momento em que escapa ao fuzilamento pelos nazistas? "Como se a morte fora dele pudesse, a partir de então, opor-se à morte nele". ${ }^{17}$ Assim nos diz o texto. E, imediatamente, escutamos as palavras de Édipo, em Colona: "Será que é no momento em que não sou nada que me torno um homem?"18

São estas palavras de Blanchot que aqui evoco para que escutemos as outras, aquelas que a Senhora H. repetia, insistentemente, enquanto trabalhávamos as "superfícies de poema": "Eu era cheia de vida. Agora já não vivo mais. Estou morta."

Repetidas como um mantra, essas palavras evocavam também a cena daquela que, um dia, querendo "pular desse barco" - a vida - saltara da janela de sua casa. Mas não morrera. Escapara à morte, ela sabia. A morte falhara? Talvez não. Porque, desde então, o mantra se declinava. "Já fui cheia de vida. Agora estou morta".

Foi sempre sob o fundo desse mantra que tecemos as "superfícies de poema". A primeira seria uma caixa de guardados femininos, porque, da vida que se perdera na queda, no desastre, restavam algumas referências à feminilidade que se fora: brincos, brocados, rendas, écharpes. Isso, que agora já não aparecia sobre o corpo, vinha então escrito, nos poemas que ela me fazia ler:

\author{
Nem flores, nem frutos \\ nem guirlandas e arabescos, \\ finos temas de bordado. \\ No sorteio dos retalhos, \\ A fala caiu para mim. \\ E aqui cumpro meu recado \\ bordadeira de retalhos \\ nesse caminho sem fim.
}

Curiosamente, este poema, que traz o feminino em seu corpo textual - flores, frutos, guirlandas, arabescos, retalhos, bordados - é dedicado "a uma colcha de retalhos". E o caminho é sem fim, o poema adverte. "Está fora de causa acabar", repetimos, fazendo ecoar, escandidas, as palavras do jovem Goethe.

A segunda superfície de poema, também trazida pela Senhora H. em seu texto "mal lido", tecer-se-ia em torno da figura da casa. Essa figura, potência de escrita em Hölder, de Hólderlin, ${ }^{19}$ é também potência de memória para a Senhora H. Afinal, ela própria desenhara a planta baixa de sua casa ideal, jamais habitada.

\footnotetext{
${ }^{17}$ Blanchot. Linstant de ma mort.

${ }^{18}$ Lacan. O Seminário. Livro 2. O eu na teoria de Freud e na técnica da Psicanálise, p. 269. Nesse seminário de Lacan, essas palavras de Édipo são evocadas por Lacan como signo da emersão do sujeito no justo momento de seu fading.

${ }^{19}$ A esse respeito, ver VIDAL. Hölder, de Hölderlin: apontamentos sobre um poema-poente. (Manuscrito inédito)
} 
Foi sobre o "suporte de papel" da casa que construímos, então, novas "superfícies de poema”. As fotocópias da planta baixa, feitas em papel vegetal nas cores preto e branco, foram colorizadas por Senhora H. E, sobre cada uma das imagens, escreveu-se um texto, um texto descritivo, "objetal”, em torno de uma única letra.

Nesse momento, nosso trabalho passou a desenvolver-se na casa da Senhora H. Isso se deveu a razões práticas, para ela, e também porque era importante que fosse ali em sua casa, em sua biblioteca de livros raros, que essa nova escrita se desenvolvesse.

E porque era a sua casa - uma casa, na ocasião, em reformas - pudemos encontrar, no armário embaixo da escada, os seus inúmeros cadernos. São diários, textos em prosa, apontamentos de estudos, anotações de sonhos, contos, o que temos reunido agora em outro caderno, em que se intercalam também colagens, aquarelas, desenhos, manuscritos. "Um palimpsesto" - ela me diz. Um palimpsesto a que decidimos chamar, por sugestão de um dos secretários-textuantes desse trabalho, de Vida em jogo.

A Vida em jogo, título extraído de seus próprios escritos, não se confunde, sabemos, com o "Jogo da vida". Trata-se, antes, de um biografema ${ }^{20}$ - letra extraída da vida, sempre em jogo, a vida que pula do barco da vida mas não morre, a vida que está perpetuamente a morrer, como a Literatura, esse "estar a morrer no texto". "Entre os perigos do poço e os prazeres do jogo", adverte-nos Llansol. ${ }^{21}$ Jogo perigoso?

\section{A EXPERIÊNCIA LITERÁRIA -}

A etimologia da palavra experiência - do latim experientia, relacionada ao verbo latino perire ${ }^{22}$ - aponta para o perigo que aí, na palavra mesma, está implicado. O que dizer, então, da experiência literária? É Derrida quem, em A Farmácia de Platão, recorda-nos que a palavra é sempre pharmakós: é remédio, mas é também veneno. ${ }^{23}$

Por isso, onde há palavras estamos sempre, de alguma maneira, entre a toxidez e o bálsamo, entre a loucura e a cura. Isso nos atesta a experiência da Psicanálise. Disso nos dá silencioso testemunho a experiência literária: entre "os perigos do poço e os prazeres do jogo".

\footnotetext{
${ }^{20}$ BARTHES. Sade, Fourier, Loiola, p. 14. O biografema, método criado por Roland Barthes e explicitado em sua abordagem das obras de Sade, Fourier e Loiola, parece-me constituir-se em método também caro à construção do caso clínico. Reduzida a uma letra, a um grafema do sujeito, a vida que se escreve não deve se dispersar em detalhes obscenos da vida pessoal de um autor (ou de um paciente), mas reduzir-se ao mínimo essencial - a letra - essa partícula particular e móvel, capaz, portanto, de ser transmitida. São palavras de Barthes, em Sade, Fourier, Loiola: "Pois se, pelo artifício de uma dialéctica, é necessário que haja no Texto, destructor de qualquer sujeito, um sujeito que se deva amar, esse sujeito está disperso, um pouco como as cinzas que se lançam ao vento depois da morte (...) Se fosse escritor, e morto, como gostaria que a minha vida se reduzisse, pelos cuidados de um amigável e desenvolto biógrafo, a alguns pormenores, a alguns gostos, a algumas inflexões, digamos: biografemas (...)".

${ }^{21}$ Llansol. Amar um cão.

${ }^{22}$ Houalss. Dicionário Houaiss de Lingua Portuguesa.

${ }^{23}$ Derrida. A farmácia de Platão.
} 
E é Lacan quem, ao final de um escrito eminentemente clínico, vem a assinalar um importante ponto de tangência entre as experiências psicanalítica e literária. Diz Lacan, em A direção do tratamento:

Já que se trata de tomar o desejo e que ele só pode ser tomado ao pé da letra, porquanto são as redes da letra que determinam e que sobredeterminam seu lugar de pássaro celeste, como não exigir do passarinheiro que ele seja, antes de mais nada, um letrado?

Da parte "literária" da obra de Freud, como um professor de Literatura em Zurique que começou a soletrá-la, quem dentre nós tentou articular a importância? ${ }^{24}$

Esse ponto de tangência nós o encontraremos na letra. Ou, melhor dizendo, na prática da letra. Enquanto práticas da letra, tanto a Psicanálise quanto a Literatura se tocam, pelo viés de experiências do soletrar aquilo que se diz, aquilo que se escreve.

Trata-se, pois, de um só-letrar, que tanto a experiência psicanalítica quanto a experiência literária testemunham. Com essa Senhora H., tenho só letrado, há cerca de um ano, a seu lado. "Só com você tenho convivido" - ela me diz, inesperadamente, interrompendo seu mantra, enquanto desenha, sobre a superfície do papel, as letras de seu nome.

São pequenos gestos. Gestos pequenos demais, os da escrita. Porque o escritor (ou o louco) é aquele que escutou coisas grandes demais para suas orelhas, que viu coisas grandes demais para seus olhos. "Do que viu e ouviu, o escritor regressa com os olhos vermelhos, com os tímpanos perfurados." ${ }^{5}$

Sim, são pequenos gestos. Gestos de um conviver, gestos de um condoer e, às vezes, até mesmo de um comemorar. ${ }^{26}$ Pequenos gestos de escrita, afinal: gestos "de compaciência pelos corpos que sofrem e de alegria pelos que amam". ${ }^{27}$

\section{RÉSUMÉ}

Description d'une pratique de la lettre comme atélier d'écriture, ayant comme méthode la textualité de Maria Gabriela Llansol, articulée à la psychanalyse lacanienne.

\section{MOTS-CLÉS}

pratique de la lettre, atélier d'écriture, textualité, psychanalyse lacanienne

\footnotetext{
${ }^{24}$ LaCAN. A direção do tratamento e os princípios de seu poder. Relatório do Colóquio de Royaumont. 10-13 de julho de 1958, p. 648.

${ }^{25}$ Deleuze. Crítica e clínica, p. 14.

26 "Comemorar", do latim "comemorare", relaciona-se à memória, ao que se lembra. "Comemoro"= "lembrar-se de". Cf. HouAIss. Op. cit.

${ }^{27}$ Llansol. Carta a Eduardo Prado Coelho. (Manuscrito inédito)
} 


\section{REFERÊNCIAS BIBLIOGRÁFICAS}

Araújo, Cinara de. O suporte de papel. In: Chaves, Maria Lúcia Resende de (Org.). Asapalavra. Brumadinho: Faculdade Asa, v.1, n.1, jan-jun. 2004.

BARThes, Roland. O rumor da língua. SP: Brasiliense, 1988. p.300-309: Malogramos sempre ao falar do que amamos.

Barthes, Roland. Sade, Fourier, Loiola. Lisboa: Edições 70, 1979.

Blanchot, Maurice. L'instant de ma mort. Paris: Fata Morgana, 1994.

Blanchot, Maurice. O espaço literário. Rio de Janeiro: Rocco, 1987.

Blanchot, Maurice. O livro por vir. Lisboa: Relógio D’Água, 1984. p. 36: Está fora de causa acabar bem.

Blanchot, Maurice. La bête de Lascaux. Paris: Fata Morgana, 1982.

Blanchot, Maurice. L'écriture du désastre. Paris: Gallimard, 1980.

Branco, Lucia Castello (Org.). Coisa de louco. Belo Horizonte: Mazza, 1998.

Deleuze, Gilles. Crítica e clínica. São Paulo: Editora 34, 1998.

DERRIDA, Jacques. A farmácia de Platão. 2. ed. São Paulo: Iluminuras, 1997.

DurAs, Marguerite. Escrever. Rio de Janeiro: Rocco, 1994.

Houaiss, Antônio. Dicionário Houaiss de Lingua Portuguesa. Rio de Janeiro: Objetiva, 2001.

LACAN, Jacques. O Seminário. Livro 2. O eu na teoria de Freud e na técnica da Psicanálise. 2. ed. Rio de Janeiro: Zahar, 1987.

LACAN, Jacques. Lituraterra. Che vuoi, Porto Alegre, Cooperativa Cultural Jacques Lacan, v. 1, n. 1, p. 21, 1986.

LACAN, Jacques. A direção do tratamento e os princípios de seu poder. Relatório do Colóquio de Royaumont. 10-13 de julho de 1958. La Psychanalyse, Paris, Sociedade Francesa de Psicanálise, v. 6, s.d., p. 648.

Llansol, Maria Gabriela. Carta a Eduardo Prado Coelho. (Manuscrito inédito)

Llansol, Maria Gabriela. Hölder, de Hölderlin. Colares: Colares, 1994.

Llansol, Maria Gabriela. Um beijo dado mais tarde. Lisboa: Rolim, 1991.

Llansol, Maria Gabriela. Amar um cão. Colares: Colares, 1990.

NANCY, Jean Luc. Noli me tangere. Paris: Bayard, 2003.

VIDAL, Eduardo. Hölder, de Hölderlin: apontamentos sobre um poema-poente. (Manuscrito inédito) 